\title{
High expression of TROP2 correlates with poor prognosis in pancreatic cancer
}

\author{
D Fong ${ }^{*, 1,2}$, P Moser ${ }^{3}$, C Krammel $^{2}$, JM Gostner ${ }^{2}$, R Margreiter ${ }^{4}$, M Mitterer $^{5}$, G Gastl' and G Spizzo $^{2,5}$ \\ 'Department of Hematology and Oncology, Innsbruck Medical University, Innsbruck 6020, Austria; ${ }^{2}$ Tyrolean Cancer Research Institute, Innsbruck 6020 , \\ Austria; ${ }^{3}$ Department of Pathology, Innsbruck Medical University, Innsbruck 6020, Austria; ${ }^{4}$ Department of General and Transplant Surgery, Innsbruck \\ Medical University, Innsbruck 6020, Austria; ${ }^{5}$ Department of Oncology and Hematology, Franz Tappeiner Hospital, Merano 390 I 2, Italy
}

Pancreatic cancer is one of the most devastating human malignancies. Despite considerable research efforts, it remains resistant to almost all available treatment regimens. The human trophoblast cell-surface antigen, TROP2, was found to be strongly expressed in a variety of human epithelial cancers, correlating with aggressiveness and poor prognosis. TROP2 antigen expression was investigated retrospectively by immunohistochemistry in paraffin-embedded primary tumour tissue samples from a series $(n=197)$ of consecutive patients with pancreatic adenocarcinoma. Survival was calculated using Kaplan-Meier curves. Parameters found to be of prognostic significance in univariate analysis were verified in a multivariate Cox regression model. TROP2 overexpression was observed in 109 (55\%) of 197 pancreatic cancer patients and was significantly associated with decreased overall survival $(P<0.01)$. By univariate analysis, TROP2 overexpression was found to correlate with the presence of lymph node metastasis $(P=0.04)$ and tumour grade $(P=0.0 \mathrm{I})$. Furthermore, in the subgroup of patients treated surgically with curative intent, TROP2 overexpression significantly correlated with poor progression-free survival $(P<0.0 \mathrm{I})$. Multivariate analyses revealed TROP2 to be an independent prognosticator. These findings suggest for the first time that TROP2 could be a novel prognostic biomarker for pancreatic cancer. Targeting TROP2 might be a useful treatment approach for patients with pancreatic cancer overexpressing this cell-surface marker.

British Journal of Cancer (2008) 99, 1290-1295. doi:10.1038/sj.bjc.6604677 www.bjcancer.com

Published online 23 September 2008

(c) 2008 Cancer Research UK

Keywords: TROP2; GA733; pancreatic cancer; targeted therapy

Pancreatic cancer is a fatal disorder. At the time of diagnosis, most patients already have locally advanced or metastatic disease excluding surgical resection (Yeo et al, 1997). Treatment regimens followed at present are ineffective and do not prolong patient survival significantly. Survival rates for the $15-20 \%$ of patients who have resectable disease at first presentation are disappointing, depending on the status of resection margins and surrounding lymph nodes. Moreover, the prognosis is poor even for those who undergo complete (R0) resection. The 5-year overall survival rate for all stages is approximately $5 \%$, whereas after radical pancreaticoduodenectomy it has been reported to range from 25 to $30 \%$ (Sohn et al, 2000; Jemal et al, 2005). To date, there are no validated prognostic indicators for identifying patients with nonmetastatic disease and good or poor prognosis. As a consequence, there is an urgent need for novel prognostic biomarkers as well as for therapeutic target structures in pancreatic cancer.

In the past, we found GA733-encoded proteins (EpCAM, TROP2) to be prognostic for a variety of epithelial cancers (Gastl et al, 2000; Varga et al, 2004; Fong et al, 2008). GA733 is a member of a family of at least two closely related genes (GA733-1; TACSTD2 and GA733-2; TACSTD1) that share sequence homology with both thyroglobulin type I and interleukin-2 receptors. The integral glycoprotein EpCAM is encoded by the GA733-2 gene functions as a homotypic intercellular adhesion molecule (Litvinov et al, 1994),

*Correspondence: Dr D Fong; E-mail: dominic.fong@i-med.ac.at Received 30 May 2008; revised 19 August 2008; accepted 26 August 2008; published online 23 September 2008 and has been targeted by antibody-mediated immunotherapy (Riethmuller et al, 1998; Ruan et al, 2003).

The human trophoblast cell-surface antigen, TROP2 (also termed GA733-1), is a transmembrane glycoprotein found to be expressed at high levels by various types of human carcinomas (Fradet et al, 1984; Stein et al, 1993a; Nakashima et al, 2004). In contrast, normal epithelial tissues show little or no TROP2 expression (Stein et al, 1993a; Zhang et al, 1997). TROP2 is encoded by the GA733-1 gene, which is intronless, formed by exon-shuffling and retroposition of the GA733-2 gene through mRNA intermediate (Linnenbach et al, 1993). Recently, TROP2 antigen expression in colorectal and squamous cell carcinomas of the oral cavity was shown to correlate with tumour aggressiveness and poor prognosis (Ohmachi et al, 2006; Fong et al, 2008). Moreover, Wang et al (2008) were able to identify TROP2 as an oncogene and an attractive therapeutic target in colon cancer. These findings indicate a potential role for TROP2 in tumour development and progression. In this retrospective study, we evaluated TROP2 antigen expression and its correlation with clinicopathologic features in pancreatic cancer.

\section{MATERIALS AND METHODS}

\section{Patients and tissue samples}

This study was conducted according to the regulations of the local Ethics Committee and Austrian law. A total number of 197 consecutive patients with pancreatic ductal adenocarcinoma, from 
whom formalin-fixed, paraffin-embedded tissue samples were available, diagnosed between 1990 and 2006 at the Department of Pathology, Innsbruck Medical University, were included in this retrospective study. Patients with other pancreatic malignancies, such as intraductal papillary mucinous adenocarcinoma, acinar cell carcinoma and malignant endocrine tumours, were excluded. All tumour specimens were reclassified on hematoxylin-and-eosinstained slides, and histological type and tumour grade were reassessed by a pathologist (PM) using standard diagnostic criteria. Clinical data were obtained by reviewing the charts and contacting the physicians in charge. Tumours were histologically classified according to the WHO classification and staged according to the tumour node metastasis classification (Sobin and Fleming, 1997). Overall survival was defined as the period of time from initial diagnosis to death or last contact, that is, date of last follow-up visit. Progression-free survival was defined as the time from surgery with curative intent to appearance of disease recurrence or evidence of new lesions detected by computed tomography.

\section{Immunohistochemistry}

TROP2 expression was determined by immunohistochemistry using a purified goat polyclonal antibody detecting the recombinant human TROP2 extracellular domain at a dilution of $1: 50$ (AF650, R\&D Systems, Inc., Minneapolis, MN, USA) as described earlier (Fong et al, 2008). Colon carcinoma samples with various TROP2 expression levels (no, low, moderate, or high expression) were used as positive and negative controls. In addition, 10 samples of normal pancreatic tissue were collected from patients undergoing pancreatic surgery at Innsbruck Medical University. TROP2 antigen overexpression was evaluated by two independent observers (PM and DF) using light microscopy in a blinded manner. Discordant cases were reevaluated on a double-headed microscope to achieve a consensus. Antigen expression was defined as the presence of specific staining on surface membranes of tumour cells. TROP2 overexpression was evaluated for each tissue sample by calculating a total immunostaining score as the product of a proportion and intensity score. The proportion score described the estimated fraction of positive-stained tumour cells ( 0 , none; $1,<10 \% ; 2,10-50 \% ; 3,51-80 \% ; 4,>80 \%)$. The intensity score represented the estimated staining intensity $(0$, no staining; 1 , weak; 2 , moderate; 3 , strong). The total score ranged from 0 to 12. As described earlier, TROP2 'overexpression' was defined as a total score of more than 4 (Fong et al, 2008). Representative micrographs of tumours with predominant membranous staining of TROP2 are shown in Figure 1.

\section{Statistical analysis}

Statistical analysis was performed using the Statistical Package of Social Sciences (SPSS, version 10.0, Chicago, IL, USA). Correlations between TROP2 expression and clinicopathological variables were assessed with the $\chi^{2}$-test. Survival rates were calculated using the Kaplan-Meier method and compared by means of the log-rank test. Follow-up time was censored if the patient was lost during follow-up. Factors with prognostic significance in the univariate models were further evaluated in a multivariate Cox regression model. For all analyses, a $P$-value of less than 0.05 was considered statistically significant.

\section{RESULTS}

\section{Patient characteristics}

Demographic data and tumour characteristics are summarised in Table 1. At the time of last clinical follow-up (February 2008), 155 (79\%) patients out of the total group had died. Median overall
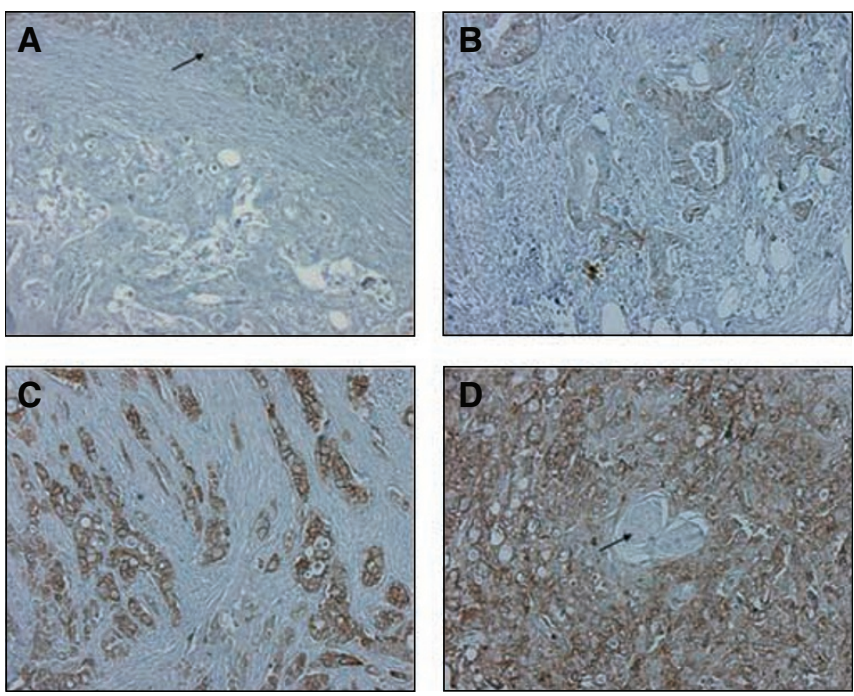

Figure I TROP2 immunostaining in pancreatic tissue, original magnification $\times 100$. (A) TROP2-negative tumour sample (score 0), normal pancreatic tissue (arrow) showing weak (score 2) immunostaining. Pancreatic ductal adenocarcinoma with moderate (score 6) (B) and strong (score 12) (C and D) TROP2 expression, note the TROP2-negative islets of Langerhans (arrow)

survival was 9 months (range, 1-68). Most patients (68\%) had undergone primary surgical intervention, whereas $54(27 \%)$ patients were considered inoperable ( 9 cases unknown). Palliative surgery included palliative bypass or endoscopic bile duct stenting. If indicated, patients received standard gemcitabine-based chemotherapy according to their clinical stage and performance status. In 17 patients, exact staging according to UICC was not feasible.

\section{Immunohistochemistry}

As reported earlier, islets of Langerhans displayed no TROP2 staining (Stein et al, 1993a), whereas in normal pancreatic epithelium TROP2 expression was weak to moderate (Figure 1). In contrast, moderate-to-strong homogeneous membranous expression of TROP2 was detected in 109 (55\%) of 197 carcinoma specimens. Strong TROP2 expression (score 9-12) was found in 57 $(29 \%)$ of 197 cases, moderate expression (score 6-8) in $52(26 \%)$ cases, weak expression (score 1-4) in $76(39 \%)$ cases and absent expression (score 0$)$ in $12(6 \%)$ of 197 cases. Thus, according to our earlier defined criteria (Fong et al, 2008), TROP2 was found to be overexpressed in 109 (55\%) of 197 cases.

\section{Clinicopathological variables and patient survival}

Univariate analysis showed TROP2 overexpression to be significantly correlated with histologic grading $(P=0.01)$ and the presence of lymph node metastases $(P=0.04)$, but not with sex, age, $\mathrm{T}$ stage, presence of distant metastasis, or involvement of the resection margin (Table 2). To assess the impact of clinicopathological features and TROP2 overexpression on survival, we used Kaplan-Meier analysis and the log-rank test for censored survival data. Consistent with earlier findings, early tumour stage and a negative resection margin were associated with longer overall survival (Table 1). It should be noted that TROP2 overexpression was significantly correlated with poor overall survival $(P<0.01$; Figure 2). Median overall survival time for patients with tumour presenting with and without TROP2 overexpression was 8 and 14 months, respectively. Overall survival gradually declined with 
Table I Patient characteristics

\begin{tabular}{|c|c|c|}
\hline \multirow[b]{2}{*}{ Variable } & \multicolumn{2}{|c|}{ Pancreatic cancer } \\
\hline & (n) (\%) & $\begin{array}{c}\text { P-value } \\
\text { (log-rank test) }\end{array}$ \\
\hline \multicolumn{3}{|l|}{$\operatorname{Sex}(n=197)$} \\
\hline Male & III (56) & 0.80 \\
\hline Female & $86(44)$ & \\
\hline \multicolumn{3}{|l|}{ Age $(n=197)$} \\
\hline Mean & 65 & \\
\hline Median & 67 & \\
\hline Range & $37-91$ & \\
\hline \multicolumn{3}{|c|}{ T stage $(\mathrm{n}=176)$} \\
\hline PTI & $13(7)$ & $<0.01$ \\
\hline pT2 & $52(29)$ & \\
\hline pT3 & $80(46)$ & \\
\hline PT4 & $31(18)$ & \\
\hline \multicolumn{3}{|c|}{ Lymph node status $(\mathrm{n}=176)$} \\
\hline Negative & 65 (37) & $<0.01$ \\
\hline Positive & III (63) & \\
\hline \multicolumn{3}{|c|}{ Distant metastasis $(\mathrm{n}=142)$} \\
\hline No & $117(82)$ & $<0.01$ \\
\hline Yes & $25(18)$ & \\
\hline \multicolumn{3}{|c|}{ Surgical margin $(n=128)$} \\
\hline Negative & $86(67)$ & $<0.01$ \\
\hline Positive & $42(33)$ & \\
\hline \multicolumn{3}{|c|}{ Stage (UICC) $(n=180)$} \\
\hline IA & $6(3)$ & $<0.01$ \\
\hline IB & $24(13)$ & \\
\hline$\| \mathrm{A}$ & $34(19)$ & \\
\hline$\| \mathrm{B}$ & $70(39)$ & \\
\hline III & $20(11)$ & \\
\hline IV & $26(15)$ & \\
\hline \multicolumn{3}{|c|}{ Differentiation $(\mathrm{n}=|8|)$} \\
\hline Well & $24(13)$ & 0.07 \\
\hline Moderate & $84(47)$ & \\
\hline Poor & $73(40)$ & \\
\hline \multicolumn{3}{|c|}{ TROP2 overexpression $(n=197)$} \\
\hline Yes & $109(55)$ & $<0.01$ \\
\hline No & $88(45)$ & \\
\hline
\end{tabular}

increasing TROP2 scores. In the subset of patients with tumours lacking TROP2 overexpression (score 0 ), median overall survival time was 15 months and decreased to 14 months (score 1-4), 10 months (score 5-8) and 7 months (score 9-12) with increasing staining scores. Multivariate analysis identified TROP2 overexpression together with a negative resection margin as an independent prognostic factor for poor overall survival (Table 3a). Subsequently, a detailed analysis for the subgroup of patients who underwent surgery with curative intent $(n=134)$ was performed.

\section{Resected cohort with curative intent}

Data on relapse or disease progression were available in $78 \%$ $(n=105)$ of the patients. Median overall and progression-free survival was 13 (range, 1-68) months and 6 (range, 1-56) months, respectively. Survival analyses revealed that TROP2 overexpression was significantly correlated with poor overall survival $(P<0.01$; Figure $3 \mathrm{~A}$ ) as well as a shortened progression-free interval
Table 2 Correlation of TROP2 overexpression with conventional clinicopathological parameters

\begin{tabular}{|c|c|c|c|c|}
\hline & \multirow[b]{2}{*}{ Total patients $(n)$} & \multicolumn{2}{|c|}{ TROP2 overexpression } & \multirow[b]{2}{*}{ P-value } \\
\hline & & $\begin{array}{c}\text { No } \\
\text { n (\%) }\end{array}$ & $\begin{array}{c}\text { Yes } \\
\text { n (\%) }\end{array}$ & \\
\hline \multicolumn{5}{|l|}{$\operatorname{Sex}(n=197)$} \\
\hline Male & || $\mid$ & $51(46)$ & $60(54)$ & 0.68 \\
\hline Female & 86 & $37(43)$ & $49(57)$ & \\
\hline \multicolumn{5}{|c|}{ Age at diagnosis $(n=197)$} \\
\hline$<65$ years & 84 & $37(44)$ & $47(56)$ & 0.88 \\
\hline$\geqslant 65$ years & 113 & $51(45)$ & $62(55)$ & \\
\hline \multicolumn{5}{|c|}{ Differentiation $(\mathrm{n}=181)$} \\
\hline Well & 24 & $17(7 \mid)$ & 7 (29) & 0.01 \\
\hline Moderate & 84 & $38(45)$ & $46(55)$ & \\
\hline Poor & 73 & $26(36)$ & $47(64)$ & \\
\hline \multicolumn{5}{|c|}{$T$ stage $(n=176)$} \\
\hline pTI & 13 & $5(38)$ & $8(62)$ & 0.06 \\
\hline pT2 & 52 & $27(52)$ & $25(48)$ & \\
\hline рT3 & 80 & $36(45)$ & $44(55)$ & \\
\hline pT4 & 31 & $7(23)$ & $24(77)$ & \\
\hline \multicolumn{5}{|c|}{ Lymph node status $(\mathrm{n}=176)$} \\
\hline No & 65 & $34(52)$ & $31(48)$ & 0.04 \\
\hline Yes & || $\mid$ & $41(37)$ & $70(63)$ & \\
\hline \multicolumn{5}{|c|}{ Distant metastasis $(\mathrm{n}=142)$} \\
\hline No & 117 & $56(48)$ & $61(52)$ & 0.14 \\
\hline Yes & 25 & $8(32)$ & $17(68)$ & \\
\hline \multicolumn{5}{|c|}{ Surgical margin $(n=128)$} \\
\hline Negative & 86 & $45(52)$ & $41(48)$ & 0.10 \\
\hline Positive & 42 & $16(38)$ & $26(62)$ & \\
\hline \multicolumn{5}{|c|}{ Stage (UICC) $(n=180)$} \\
\hline IA & 6 & $4(67)$ & $2(33)$ & 0.03 \\
\hline $\mid \mathrm{B}$ & 24 & $15(63)$ & $9(37)$ & \\
\hline$\| A$ & 34 & $15(44)$ & $19(56)$ & \\
\hline$\| \mathrm{B}$ & 70 & $32(46)$ & $38(54)$ & \\
\hline III & 20 & $3(15)$ & $17(85)$ & \\
\hline IV & 26 & $9(35)$ & $17(64)$ & \\
\hline
\end{tabular}

$(P<0.01$; Figure 3B). Table $3 \mathrm{~b}$ shows the multivariate analyses for patients treated surgically with curative intent. This model was refined by stepwise removal of variables. Regarding overall survival, TROP2 overexpression together with a negative resection margin has been identified to be an independent prognostic marker. Concerning progression-free survival, TROP2 overexpression was independent of nodal status and margin involvement by the tumour.

\section{DISCUSSION}

This study describes the prognostic value of TROP2 expression in pancreatic cancer. Overexpression of TROP2 was detectable in 109 $(55 \%)$ of 197 tumour samples and was significantly correlated with decreased overall survival. In multivariate analyses, TROP2 overexpression was shown to be an independent prognostic biomarker for poor overall survival. Furthermore, TROP2 overexpression was significantly associated with a shortened progression-free survival in the subgroup of patients who underwent surgery with curative intent.

Both cell-surface glycoproteins, TROP2 and EpCAM, are encoded by the GA733 gene family and have been efficiently 


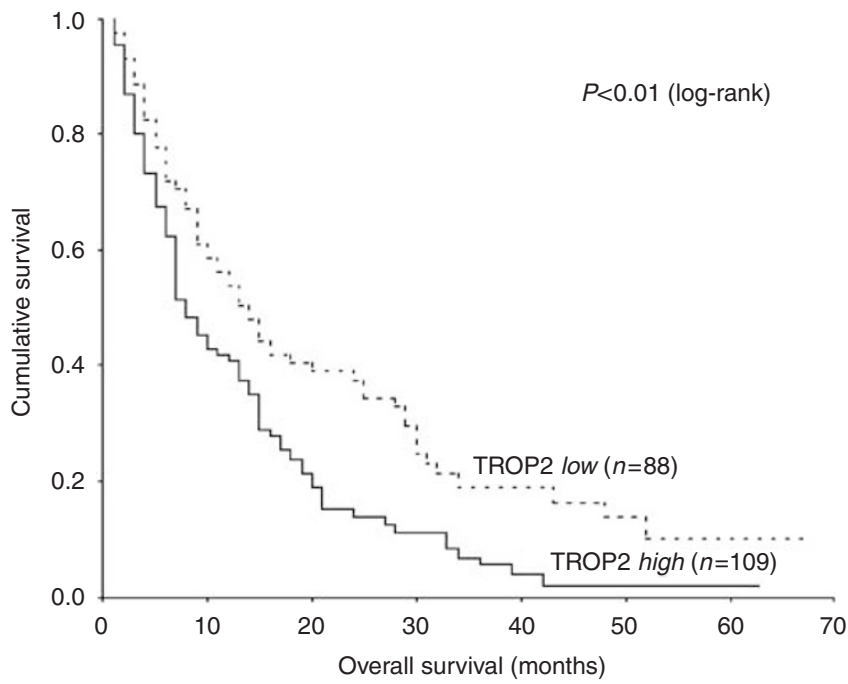

Figure 2 Prognostic significance of TROP2 antigen expression in 197 patients with pancreatic ductal adenocarcinomas regarding overall survival as calculated by Kaplan-Meier analysis. Low, patients with tumour $(n=88)$ without TROP2 overexpression; high, patients with tumour $(n=109)$ with TROP2 overexpression. Patients with low TROP2 expression had significantly better overall survival than patients with high TROP2 expression as defined by the log-rank test $(P<0.0 \mathrm{I})$.

Table 3 Multivariate analyses (Cox regression) of various prognostic parameters in the total cohort and subgroup of patients with curative intent

\begin{tabular}{|c|c|c|c|c|c|c|}
\hline & & & & \multicolumn{3}{|c|}{ Overall survival } \\
\hline & & & & $P$-value & $\mathbf{R R}$ & $95 \% \mathrm{Cl}$ \\
\hline \multicolumn{7}{|c|}{ (a) Total group of patients $(\mathrm{n}=197)$} \\
\hline T stage & & & & 0.81 & 1.0 & $0.7-1.4$ \\
\hline Nodal status & & & & 0.94 & 0.9 & $0.5-1.6$ \\
\hline Distant metastasis & & & & 0.71 & 0.7 & $0.1-5.2$ \\
\hline Surgical margin & & & & 0.02 & 1.9 & $1.1-3.5$ \\
\hline \multirow[t]{3}{*}{ TROP2 overexpression } & & & & 0.01 & 1.8 & $1.1-3.1$ \\
\hline & \multicolumn{3}{|c|}{$\begin{array}{c}\text { Progression-free } \\
\text { survival }\end{array}$} & \multicolumn{3}{|c|}{$\begin{array}{l}\text { Overall } \\
\text { survival }\end{array}$} \\
\hline & $P$-value & $\mathbf{R R}$ & $95 \% \mathrm{Cl}$ & $P$-value & $\mathbf{R R}$ & $95 \% \mathrm{Cl}$ \\
\hline \multicolumn{7}{|c|}{ (b) Subgroup of patients treated surgically with curative intent $(n=134)$} \\
\hline T stage & 0.720 & 0.9 & $0.6-1.3$ & 0.721 & 0.9 & $0.6-1.3$ \\
\hline Nodal status & 0.545 & 1.1 & $0.6-2.1$ & 0.764 & 0.9 & $0.5-1.5$ \\
\hline Surgical margin & 0.276 & 1.4 & $0.7-2.7$ & 0.012 & 2.0 & $1.1-3.5$ \\
\hline TROP2 overexpression & 0.070 & 1.6 & $0.9-2.8$ & 0.009 & 1.8 & $1.1-3.0$ \\
\hline Nodal status & 0.562 & 1.1 & $0.6-2.1$ & 0.772 & 0.9 & $0.5-1.5$ \\
\hline Surgical margin & 0.301 & 1.3 & $0.7-2.6$ & 0.012 & 1.9 & $1.1-3.3$ \\
\hline TROP2 overexpression & 0.073 & 1.6 & $0.9-2.7$ & 0.009 & 1.8 & $1.1-3.0$ \\
\hline Surgical margin & 0.185 & 1.4 & $0.8-2.7$ & 0.009 & 1.9 & $1.1-3.1$ \\
\hline TROP2 overexpression & 0.053 & 1.6 & $0.9-2.8$ & 0.009 & 1.8 & $1.1-2.9$ \\
\hline Nodal status & 0.193 & 1.3 & $0.8-2.2$ & 0.288 & 1.2 & $0.8-1.9$ \\
\hline TROP2 overexpression & 0.014 & 1.8 & $1.1-2.9$ & 0.000 & 2.0 & $1.3-3.1$ \\
\hline
\end{tabular}

Abbreviations: $\mathrm{Cl}=$ confidence Interval; $\mathrm{RR}=$ relative risk.

targeted by monoclonal antibodies in vitro as well as in vivo (Velders et al, 1998; Ruan et al, 2003; Wang et al, 2008). Similarly TROP2, EpCAM overexpression was also found to be a strong
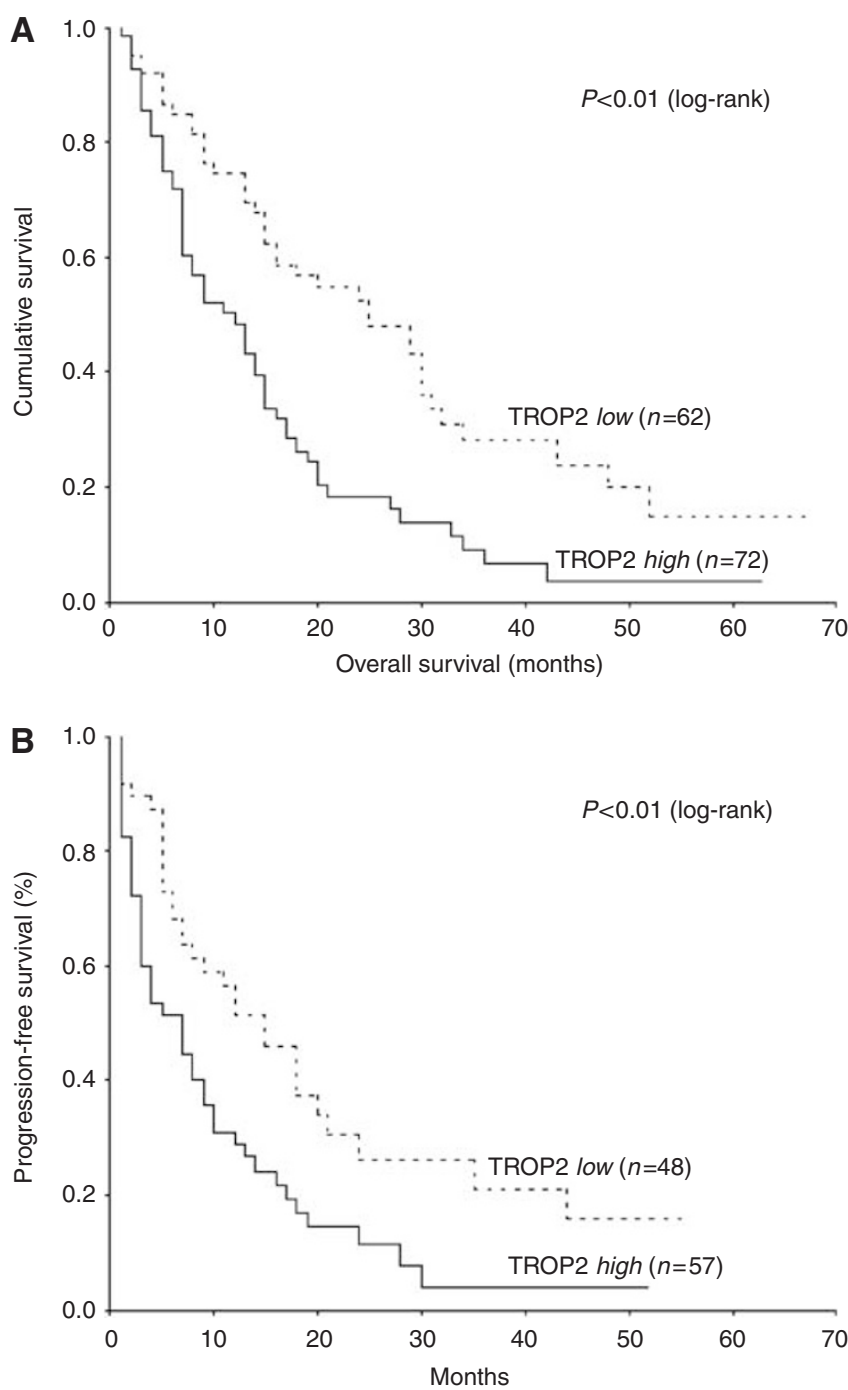

Figure 3 Prognostic significance of TROP2 antigen expression in the subgroup of patients who underwent surgery with curative intent regarding overall $(n=134)$ and progression-free $(n=105)$ survival as calculated by Kaplan-Meier analysis. Patients with tumour tissue presenting TROP2 overexpression (TROP2 high) had a significant shortened overall survival (A) and progression-free (B) interval as compared with patients with tumours lacking TROP2 overexpression (TROP2 low).

prognostic marker for poor survival in various epithelial cancer entities (Gastl et al, 2000; Varga et al, 2004; Stoecklein et al, 2006). Owing to its immunogenic properties in cancer patients, active and passive immunotherapeutic agents against the EpCAM antigen have been developed (Riethmuller et al, 1998; de Bono et al, 2004).

The functional role of TROP2 in carcinogenesis and tumour progression is only poorly understood. Fornaro et al (1995), who first cloned the human TROP2 gene, speculated that TROP2 might be a cell-surface signal transducer and might regulate tumour cell proliferation. This assumption is substantiated by the finding that the cytoplasmic domain of TROP2 contains several potential phosphorylation sites and TROP2 cross-linking antibodies can cause a transient increase in intracellular calcium levels (Basu et al, 1995; Ripani et al, 1998). Moreover, it has been shown that human cancer cells can express an oncogenic hybrid mRNA between TROP2 and cyclin D1, a master regulator of the cell cycle (Terrinoni et al, 2001). Interestingly, TROP2 seems to be involved 
in regulating the shift between cell migration and differentiation in primordium cells (Villablanca et al, 2006). However, its physiological ligand is still unknown. Schon et al (1993) were able to demonstrate that EpCAM can undergo proteolytic processing and that cleavage may activate EpCAM signalling. Similar mechanisms have been hypothesised for TROP2 (Fornaro et al, 1995). Recently, TROP2 expression was shown to correlate with invasive tumour phenotypes and poor prognosis (Ohmachi et al, 2006; Fong et al, 2008). In pancreatic cancer, TROP 2 was previously reported to be highly expressed (Iacobuzio-Donahue et al, 2002), whereas Wang et al (2008) identified TROP2 as an oncogene and a potential therapeutic target in colon cancer. In fact, blocking experiments with anti-TROP2 antibodies revealed that TROP2 can contribute to tumour cell migration and invasion. Moreover, increasing TROP2 expression prompted an anchorage-independent growth of colon cancer cells.

The murine monoclonal antibody (mAb) RS7 reacts specifically with TROP2 and exhibits functional properties that make it an attractive tool for clinical diagnostic and therapeutic applications
(Stein et al, 2003b). Indeed, radiolabelled RS7 has been applied for tumour imaging and revealed significant antitumour activity in several animal models (Shih et al, 1995; Stein et al, 1999c). Meanwhile, RS7 was successfully humanised and showed promising antitumour effects in an in vivo breast cancer model (Govindan et al, 2004).

In conclusion, we have demonstrated that TROP2 is a novel prognostic biomarker for pancreatic adenocarcinoma. These data must be confirmed and validated prospectively. Furthermore, TROP2 harbours the potential to become an attractive target for antibody-based therapies for the subset of patients with TROP2-overexpressing pancreatic cancer.

\section{ACKNOWLEDGEMENTS}

This study was supported by the ÖNB Grant 12168 and the Österreichische Krebshilfe-Krebsgesellschaft Tirol. We thank Ines Brosch for excellent technical assistance.

\section{REFERENCES}

Basu A, Goldenberg DM, Stein R (1995) The epithelial/carcinoma antigen EGP-1, recognized by monoclonal antibody RS7-3G11, is phosphorylated on serine 303. Int J Cancer 62: $472-479$

de Bono JS, Tolcher AW, Forero A, Vanhove GF, Takimoto C, Bauer RJ, Hammond LA, Patnaik A, White ML, Shen S, Khazaeli MB, Rowinsky EK, LoBuglio AF (2004) ING-1, a monoclonal antibody targeting Ep-CAM in patients with advanced adenocarcinomas. Clin Cancer Res 10: 7555 - 7565

Fong D, Spizzo G, Gostner JM, Gastl G, Moser P, Krammel C, Gerhard S, Rasse M, Laimer K (2008) TROP2: a novel prognostic marker in squamous cell carcinoma of the oral cavity. Mod Pathol 21: 186-191

Fornaro M, Dell'Arciprete R, Stella M, Bucci C, Nutini M, Capri MG, Alberti S (1995) Cloning of the gene encoding Trop-2, a cell-surface glycoprotein expressed by human carcinomas. Int J Cancer 62: 610-618

Fradet Y, Cordon-Cardo C, Thomson T, Daly ME, Whitmore Jr WF, Lloyd KO, Melamed MR, Old LJ (1984) Cell surface antigens of human bladder cancer defined by mouse monoclonal antibodies. Proc Natl Acad Sci USA 81: $224-228$

Gastl G, Spizzo G, Obrist P, Dunser M, Mikuz G (2000) Ep-CAM overexpression in breast cancer as a predictor of survival. Lancet 356: $1981-1982$

Govindan SV, Stein R, Qu Z, Chen S, Andrews P, Ma H, Hansen HJ, Griffiths GL, Horak ID, Goldenberg DM (2004) Preclinical therapy of breast cancer with a radioiodinated humanized anti-EGP-1 monoclonal antibody: advantage of a residualizing iodine radiolabel. Breast Cancer Res Treat 84: $173-182$

Iacobuzio-Donahue CA, Maitra A, Shen-Ong GL, van Heek T, Ashfaq R, Meyer R, Walter K, Berg K, Hollingsworth MA, Cameron JL, Yeo CJ, Kern SE, Goggins M, Hruban RH (2002) Discovery of novel tumor markers of pancreatic cancer using global gene expression technology. Am J Pathol 160: 1239-1249

Jemal A, Murray T, Ward E, Samuels A, Tiwari RC, Ghafoor A, Feuer EJ, Thun MJ (2005) Cancer statistics, 2005. CA Cancer J Clin 55: 10-30

Linnenbach AJ, Seng BA, Wu S, Robbins S, Scollon M, Pyrc JJ, Druck T, Huebner K (1993) Retroposition in a family of carcinoma-associated antigen genes. Mol Cell Biol 13: $1507-1515$

Litvinov SV, Velders MP, Bakker HA, Fleuren GJ, Warnaar SO (1994) Ep-CAM: a human epithelial antigen is a homophilic cell-cell adhesion molecule. J Cell Biol 125: 437-446

Nakashima K, Shimada H, Ochiai T, Kuboshima M, Kuroiwa N, Okazumi S, Matsubara H, Nomura F, Takiguchi M, Hiwasa T (2004) Serological identification of TROP2 by recombinant cDNA expression cloning using sera of patients with esophageal squamous cell carcinoma. Int J Cancer 112: $1029-1035$

Ohmachi T, Tanaka F, Mimori K, Inoue H, Yanaga K, Mori M (2006) Clinical significance of TROP2 expression in colorectal cancer. Clin Cancer Res 12: $3057-3063$

Riethmuller G, Holz E, Schlimok G, Schmiegel W, Raab R, Hoffken K, Gruber R, Funke I, Pichlmaier H, Hirche H, Buggisch P, Witte J,
Pichlmayr R (1998) Monoclonal antibody therapy for resected Dukes' C colorectal cancer: seven-year outcome of a multicenter randomized trial. J Clin Oncol 16: $1788-1794$

Ripani E, Sacchetti A, Corda D, Alberti S (1998) Human Trop-2 is a tumorassociated calcium signal transducer. Int J Cancer 76: 671-676

Ruan HH, Scott KR, Bautista E, Ammons WS (2003) ING-1(heMAb), a monoclonal antibody to epithelial cell adhesion molecule, inhibits tumor metastases in a murine cancer model. Neoplasia 5: 489-494

Schon MP, Schon M, Mattes MJ, Stein R, Weber L, Alberti S, Klein CE (1993) Biochemical and immunological characterization of the human carcinoma-associated antigen $\mathrm{MH}$ 99/KS 1/4. Int J Cancer 55: 988-995

Shih LB, Xuan H, Aninipot R, Stein R, Goldenberg DM (1995) In vitro and in vivo reactivity of an internalizing antibody, RS7, with human breast cancer. Cancer Res 55: 5857s-5863s

Sobin LH, Fleming ID (1997) TNM Classification of Malignant Tumors, fifth edition (1997). Union Internationale Contre le Cancer and the American Joint Committee on Cancer. Cancer 80: 1803-1804

Sohn TA, Yeo CJ, Cameron JL, Koniaris L, Kaushal S, Abrams RA, Sauter PK, Coleman J, Hruban RH, Lillemoe KD (2000) Resected adenocarcinoma of the pancreas-616 patients: results, outcomes, and prognostic indicators. J Gastrointest Surg 4: 567-579

Stein R, Basu A, Chen S, Shih LB, Goldenberg DM (1993a) Specificity and properties of MAb RS7-3G11 and the antigen defined by this pancarcinoma monoclonal antibody. Int J Cancer 55: 938-946

Stein R, Govindan SV, Mattes MJ, Chen S, Reed L, Newsome G, McBride BJ, Griffiths GL, Hansen HJ, Goldenberg DM (2003b) Improved iodine radiolabels for monoclonal antibody therapy. Cancer Res 63: $111-118$

Stein R, Govindan SV, Mattes MJ, Shih LB, Griffiths GL, Hansen HJ, Goldenberg DM (1999c) Targeting human cancer xenografts with monoclonal antibodies labeled using radioiodinated, diethylenetriaminepentaacetic acid-appended peptides. Clin Cancer Res 5: 3079s-3087s

Stoecklein NH, Siegmund A, Scheunemann P, Luebke AM, Erbersdobler A, Verde PE, Eisenberger CF, Peiper M, Rehders A, Esch JS, Knoefel WT, Hosch SB (2006) Ep-CAM expression in squamous cell carcinoma of the esophagus: a potential therapeutic target and prognostic marker. $B M C$ Cancer 6: 165

Terrinoni A, Dell'Arciprete R, Fornaro M, Stella M, Alberti S (2001) Cyclin D1 gene contains a cryptic promoter that is functional in human cancer cells. Genes Chromosomes Cancer 31: 209-220

Varga M, Obrist P, Schneeberger S, Muhlmann G, Felgel-Farnholz C, Fong D, Zitt M, Brunhuber T, Schafer G, Gastl G, Spizzo G (2004) Overexpression of epithelial cell adhesion molecule antigen in gallbladder carcinoma is an independent marker for poor survival. Clin Cancer Res 10: 3131 - 3136

Velders MP, van Rhijn CM, Oskam E, Fleuren GJ, Warnaar SO, Litvinov SV (1998) The impact of antigen density and antibody affinity on antibodydependent cellular cytotoxicity: relevance for immunotherapy of carcinomas. $\mathrm{Br}$ J Cancer 78: $478-483$ 
Villablanca EJ, Renucci A, Sapede D, Lec V, Soubiran F, Sandoval PC, Dambly-Chaudiere C, Ghysen A, Allende ML (2006) Control of cell migration in the zebrafish lateral line: implication of the gene 'TumourAssociated Calcium Signal Transducer,' tacstd. Dev Dyn 235: 1578-1588 Wang J, Day R, Dong Y, Weintraub SJ, Michel L (2008) Identification of Trop-2 as an oncogene and an attractive therapeutic target in colon cancers. Mol Cancer Ther 7: 280-285
Yeo CJ, Cameron JL, Sohn TA, Lillemoe KD, Pitt HA, Talamini MA, Hruban RH, Ord SE, Sauter PK, Coleman J, Zahurak ML, Grochow LB, Abrams RA (1997) Six hundred fifty consecutive pancreaticoduodenectomies in the 1990s: pathology, complications, and outcomes. Ann Surg 226: 248-257

Zhang L, Zhou W, Velculescu VE, Kern SE, Hruban RH, Hamilton SR, Vogelstein B, Kinzler KW (1997) Gene expression profiles in normal and cancer cells. Science 276: $1268-1272$ 